\title{
Machine Learning in Pain Medicine: An Up-To-Date Systematic Review
}

\author{
Maria Matsangidou · Andreas Liampas · Melpo Pittara • \\ Constantinos S. Pattichi · Panagiotis Zis (D)
}

Received: June 8, 2021 / Accepted: September 7, 2021 / Published online: September 26, 2021

(C) The Author(s) 2021

\section{ABSTRACT}

Introduction: Pain is the unpleasant sensation and emotional experience that leads to poor quality of life for millions of people worldwide. Considering the complexity in understanding the principles of pain and its significant impact on individuals and society, research focuses to deliver innovative pain relief methods and techniques. This review explores the clinical uses of machine learning (ML) for the diagnosis, classification, and management of pain.

Methods: A systematic review of the current literature was conducted using the PubMed database library.

M. Matsangidou · C. S. Pattichi

CYENS Centre of Excellence, Nicosia, Cyprus

\section{A. Liampas}

Department of Neurology, Nicosia New General Hospital, Nicosia, Cyprus

\section{Pittara}

Bernoulli Institute for Mathematics Computer Science and Artificial Intelligent, University of Groningen, Groningen, Netherlands

\section{S. Pattichi}

Computer Science, University of Cyprus, Nicosia, Cyprus

\section{P. Zis $(\square)$}

Medical School, University of Cyprus, Nicosia, Cyprus

e-mail: takiszis@gmail.com
Results: Twenty-six papers related to pain and ML research were included. Most of the studies used ML for effectively classifying the patients' level of pain, followed by use of ML for the prediction of manifestation of pain and for pain management. A less common reason for performing ML analysis was for the diagnosis of pain. The different approaches are thoroughly discussed.

Conclusion: ML is increasingly used in pain medicine and appears to be more effective compared to traditional statistical approaches in the diagnosis, classification, and management of pain.

Keywords: Machine learning; Algorithms; Pain; Pain classification; Pain manifestation; Pain diagnosis; Pain management; Supervised learning; Unsupervised learning

\section{Key Summary Points}

Machine learning techniques for classifying patients' levels of pain are effective.

Machine learning techniques can be used for the classification, manifestation, diagnosis, and management of pain.

Machine learning is increasingly used in pain medicine. 


\section{INTRODUCTION}

Pain is a complex somatic and emotional phenomenon. Causes of pain are numerous and include traumas, medical diseases, and genetic disorders [1-4]. The universality of pain as a human experience and the high prevalence of pain underscore the significance of this symptom, while its complexity attracts significant attention from the research community to fully comprehend this experience.

A variety of pharmacological and non-pharmacological approaches have been used for the treatment of pain. Most pain management practices are put in place by medical and nursing staff. This highlights the imperative need to inform this community of professionals on innovative pain relief methods and techniques.

Machine learning (ML) is the use of data and algorithms to imitate the process of human thinking and learning. ML uses a set of methods to automatically detect patterns in big data to gradually inform and improve the algorithm's accuracy. Then the patterns are used to classify, predict, or extract information from future data from which the algorithm derives new knowledge. In particular, algorithms are trained to produce classifications or predictions, uncovering key insights in data mining projects through the use of statistical methods. Subsequently, these insights influence decision-making impacting key growth metrics. It is worth mentioning that these are accomplished utilizing supervised (i.e., labelled data), semi-supervised (i.e., within a large amount of unlabelled data, a small amount of data are labelled), unsupervised (i.e., unlabelled data), or reinforcement (i.e., develops patterns based on trials and errors) learning, which indicates the ability of the algorithm to independently discover, adapt, and respond to unscripted patterns and groups of data [5-7]. On the basis of the nature of the data, different techniques are used in $\mathrm{ML}$ analysis. The most common techniques are classification for supervised data (e.g., predict and categorize specific data, like the type of pain) or regression for semi-supervised and unsupervised data (e.g., predict a reaction that can cause pain, without having a prior knowledge of that reaction). The most common ML algorithms discussed in this review are presented in Table 1.

With this systematic review, we are mostly interested in exploring the clinical uses of ML related to pain. For the purpose of this review, the following specific research questions were addressed:

1. Is ML an effective solution for classifying, predicting manifestation, and managing pain?

2. What are the ML techniques mostly used in pain medicine?

3. What are the future directions of ML?

\section{METHODS}

\section{Protocol Registration}

This review was registered in PROSPERO (registration number CRD42021248001), an international database of prospectively registered systematic reviews in the context of health and social care.

\section{Compliance with Ethics Guidelines}

This article is based on previously conducted research and does not contain any studies with human participants performed by any of the authors. Therefore, ethical approval was not required.

\section{Literature Review Strategy}

A systematic literature search of the PubMed database was performed on 15 July 2021 using three Medical Subject Heading (MeSH) terms that had to be present in the title. Term A was "Machine Learning" OR "Support Vector Machines" OR "Neural Networks" OR "Deep Learning" OR "Multi-Layer Perceptrons" and term B was "Pain" OR "Painful". No filter was applied. The reference lists of articles that met the eligibility criteria were further perused to identify additional studies that may fall within the scope of this review. 
Table 1 Machine learning algorithms that have been used in pain medicine to date

\begin{tabular}{|c|c|}
\hline Machine learning algorithm & Characteristics \\
\hline Bayes $[17,19,20,22]$ & $\begin{array}{l}\text { Estimates the probability of data patterns belonging to a } \\
\text { specific class }\end{array}$ \\
\hline $\begin{array}{l}\text { Boosting: functional data boosting (FDboost) [13]; gradient } \\
\text { boosting (GB) }[24,28] \text {; extreme gradient boosting } \\
\text { regression (XGBoost) }[27,31]\end{array}$ & Merges weak classifiers into strong ones \\
\hline $\begin{array}{l}\text { Deep learning neural network (DLNN) } \\
{[10,11,14,16,18,34,35]}\end{array}$ & $\begin{array}{l}\text { Similarly to multiple linear regression it contains layers of } \\
\text { interconnected nodes. A subclass of NN is the } \\
\text { convolutional neural network (CNN) }\end{array}$ \\
\hline Decision trees $(\mathrm{DT})[14,22,29,34]$ & $\begin{array}{l}\text { Gradually reject classes assigned into multistage decision } \\
\text { systems to accept a final class. In pain medicine, decision } \\
\text { trees algorithms such as classification and regression trees } \\
\text { have been used }\end{array}$ \\
\hline k-means clustering [14] & $\begin{array}{l}\text { Divides a number of data points into a number of clusters } \\
\text { based on the nearest mean }\end{array}$ \\
\hline k-nearest neighbors $(\mathrm{kNN})[10,22,24,27,29,32]$ & $\begin{array}{l}\text { Assigns data patterns to a class on the basis of the distance to } \\
\text { the training patterns of a certain class }\end{array}$ \\
\hline Multilayer perceptron (MLP) $[9,22]$ & $\begin{array}{l}\text { Trains on a set of input data patterns to predict/classify the } \\
\text { output class }\end{array}$ \\
\hline Random forest (RF) $[14,15,28,29,31,32]$ & $\begin{array}{l}\text { Builds and merges multiple decision trees to provide a more } \\
\text { accurate prediction }\end{array}$ \\
\hline $\begin{array}{l}\text { Regression: kernel ridge regression (KRR), [30]; elastic net } \\
\text { (EN) }[23,28] \text {; generalized linear mixed-models (GLMMs) } \\
\text { based on repeated data points, Lasso [15, 24]; least square } \\
\text { (LS) [28]; linear regression (LiR) [27, 33]; logistic } \\
\text { regression (LoR) }[10,15,29,31,32] \text {; ridge regression (RR) } \\
\text { [28] }\end{array}$ & $\begin{array}{l}\text { Predicts the probability of agreement using continuous data } \\
\text { points }\end{array}$ \\
\hline $\begin{array}{l}\text { Support vector machine (SVM) } \\
\qquad[9,12,15,21,22,25-27,29,32,34]\end{array}$ & $\begin{array}{l}\text { Creates a hyperplane to separate two classes. The hyperplane } \\
\text { is found by optimizing a cost function }\end{array}$ \\
\hline Multi-subject dictionary learning (MSDL) [16] & $\begin{array}{l}\text { It is a feature learning method where a training example is } \\
\text { represented as a linear combination of basic functions, and } \\
\text { is assumed to be a sparse matrix }\end{array}$ \\
\hline
\end{tabular}

\section{Inclusion and Exclusion Criteria}

Studies eligible to be included in this review had to meet the following inclusion criteria: (1) human subjects were involved; (2) the full article was written in English; (3) papers studied ML in pain medicine.

The exclusion criteria were (1) publications where the study of pain was not the primary aim of the study; (2) publications that were not original studies (i.e., review articles, letters, 
medical hypotheses, etc.); (3) publications where ML method was not used for pain assessment; (4) publications presented trials with fewer than ten patients per treatment arm; (5) publications presented trials studying subjects less than 18 years old; (6) duplicate publications or studies referring to the exact same population; (7) publications whose abstract was not accessible; (8) publications whose full text could not be obtained.

\section{Data Collection Process}

Following identification of the eligible publications, all relevant data were collected in a structured coding scheme using an Excel file. On the basis of the aim of each study, included papers publications that used ML for pain were grouped into the following categories: (1) pain classification; (2) pain diagnosis; (3) prediction of pain manifestation; (4) pain management. The data collected included demographics, the type of pain, the ML technique, the input data size, the instruments, the results, and the level of accuracy in each ML approach. When there was uncertainty regarding how the data should be interpreted or utilized, a cross reliability test between three authors was performed.

\section{Data Synthesis}

This study used aggregated data where possible, in accordance with the Preferred Reporting Items for Systematic Reviews and Meta-Analysis (PRISMA) guidelines [8].

\section{RESULTS}

\section{Search Results}

This search strategy resulted in the identification of 100 articles. After the eligibility assessment, 78 articles were excluded. A further four

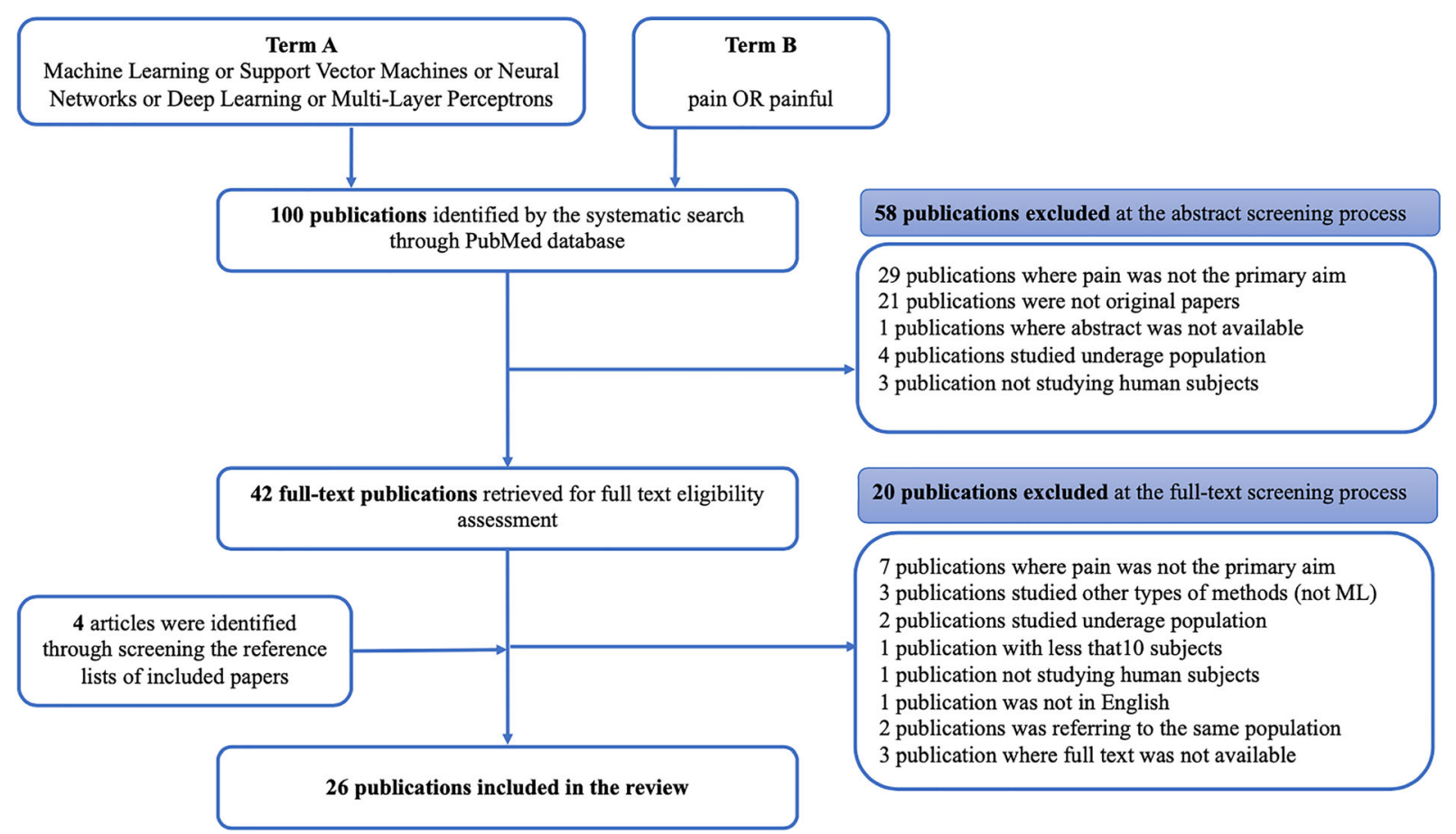

Fig. 1 PRISMA chart 
articles were identified through manually perusing the reference lists of the included articles. In total, 26 papers met the inclusion criteria and were used for this review [9-34]. These studies were published between 2015 and 2021. Figure 1 (PRISMA chart) illustrates the study selection process.

\section{Effectiveness of ML in Pain Classification, Diagnosis, Manifestation, and Management}

Table 2 presents the characteristics of the studies, including the ML method that was applied and the respective results.

ML techniques for classifying the intensity of pain were found to be effective in patients with low back pain (LBP) $[9,12,13,16]$, osteoarthritis [21], ankylosing spondylitis [30], spinal cord injury [26], thoracic pain[29], sickle cell disease (SCD) [32], evoked heat pain [25, 27], and other types of pain [15]. In their case-controlled study, Abdollahi et al. classified pain based on quantitative kinematic data. In their case-controlled study, Liew et al. collected electromyographic and kinematic data which were used to classify pain [13]. Brain functional imaging and autonomic activity (i.e., heart rate variability) data were collected by Lee et al. after back pain exacerbation maneuvers to measure pain intensity with the aid of support vector machine (SVM) [12]. In their case controlled study, Santana et al. used functional magnetic resonance imaging (fMRI) data in 60 patients with chronic pain (36 subjects with fibromyalgia and 24 subjects with low back pain) and 98 pain-free controls in order to compare the performance of different ML models in pain classification and found that $\mathrm{CNN}$, which assessed data using the MSDL probabilistic atlas, was the most efficient with balanced accuracy ranging from $69 \%$ to $86 \%$ [16]. In two studies, EEG data have been used for pain classification in patients with osteoarthritis [21] and in patients with pain due to spinal cord injury [26]. Overall, the results of these studies suggested that supervised ML algorithms can accurately classify the intensity of pain regardless of its type. For more accurate results, it was suggested to compare patients' responses with responses collected by healthy individuals [26]. In a case series study, Rojas-Mendizabal et al. performed an analysis of 27 variables, which included demographic and clinical parameters, in order to evaluate the origin of thoracic pain and determine a possible correlation between these parameters and the presence of cardiac pain, managing to obtain a mean accuracy of $96 \%$ [29]. Rogachov et al. acquired resting-state functional MRI and quantified frequencyspecific regional low-frequency oscillations (LFOs) in patients with chronic pain and ankylosing spondylitis and, using an ML approach, found that higher frequencies can be used to make generalizable inferences about patients' average pain ratings (trait-like pain) but not current (i.e., state-like) pain levels [30]. These results were also validated with healthy individuals, revealing higher brain signal variability in the dynamic pain connectome [30]. Pouromran et al. evaluated electrophysiological data of evoked heat pain from healthy subjects via different ML methods in order to predict the pain intensity and found that electrodermal activity using a support vector regression (SVR) model gave the best performance with an accuracy of $83 \%$ [27]. In their study, Gruss et al. using biopotential data and an SVR model estimated the evoked heat pain intensity and characterized the pain patterns with an accuracy of over 90\% [25]. Yang et al. used physiological measurements for 40 patients with SCD to predict their pain intensity by applying different ML methods [32]. Multinomial logistic regression (MLR) illustrated the best performance on pain prediction with a mean accuracy of 0.578 at the intra-individual level and a mean accuracy of 0.429 at the inter-individual level. Finally, a study suggested that to increase the positive outcomes of ML on pain, the predictive models of pain should consider other variables like sleep patterns which can be associated with the experience of pain, offering an accuracy of $81 \%$ [14].

Grauhan et al. used CNN for the effective diagnosis of the cause of shoulder pain on 2700 plain radiographs (X-rays) with the best accuracy to be for osteoarthritis $(87 \%)$, even when presented with poor image quality [30]. Santra 
Table 2 Summary characteristics of pain studies included in this review

\begin{tabular}{|c|c|c|c|c|}
\hline Study & Type of pain & Study population & Use of ML & Main findings \\
\hline $\begin{array}{l}\text { Abdollahi } \\
2020[9]\end{array}$ & Low back & $\begin{array}{l}94 \text { patients, age } \\
20-50 \text { years }\end{array}$ & Classification & $\begin{array}{l}\text { ML can effectively classify pain intensity based on } \\
\text { quantitative kinematic data }\end{array}$ \\
\hline Lee 2019 [12] & Low back & $\begin{array}{l}53 \text { patients, age } \\
18-60 \text { years }\end{array}$ & Classification & ML can effectively classify intensity of evoked pain \\
\hline $\begin{array}{l}\text { Liew } 2020 \\
\quad[13]\end{array}$ & Low back & $\begin{array}{l}33 \text { patients and } 16 \\
\text { controls, age } \\
18-55 \text { years }\end{array}$ & Classification & $\begin{array}{l}\text { ML can effectively classify pain intensity using } \\
\text { electromyographic and kinematic data }\end{array}$ \\
\hline $\begin{array}{l}\text { Rahman } 2018 \\
\quad[15]\end{array}$ & Various causes & 782 patients & Manifestation & $\begin{array}{l}\text { ML can effectively measure and predict pain } \\
\text { volatility }\end{array}$ \\
\hline $\begin{array}{l}\text { Santana } 2019 \\
\quad[16]\end{array}$ & $\begin{array}{l}\text { Low back } \\
\text { fibromyalgia }\end{array}$ & $\begin{array}{l}60 \text { patients and } 98 \\
\text { controls, age } \\
18-55 \text { years }\end{array}$ & Classification & $\begin{array}{l}\text { ML can effectively classify pain intensity using } \\
\text { fMRI data }\end{array}$ \\
\hline $\begin{array}{l}\text { Snyder } 2021 \\
\quad[18]\end{array}$ & Low back & 10 subjects & Manifestation & $\begin{array}{l}\text { ML can classify the relative risk of low back pain } \\
\text { due to lifting activities, using gyroscope and } \\
\text { accelerometer data }\end{array}$ \\
\hline $\begin{array}{l}\text { Kimura } 2021 \\
\quad[21]\end{array}$ & Osteoarthritis & $\begin{array}{l}23 \text { patients, age } \\
44-80 \text { years }\end{array}$ & Classification & ML can effectively classify pain using EEG data \\
\hline $\begin{array}{l}\text { Levitt } 2020 \\
\quad[26]\end{array}$ & $\begin{array}{l}\text { Spinal cord } \\
\text { injury }\end{array}$ & $\begin{array}{l}37 \text { patients and } 20 \\
\text { controls, age } \\
\geq 25 \text { years }\end{array}$ & Classification & ML can effectively classify pain using EEG data \\
\hline $\begin{array}{l}\text { Rojas- } \\
\qquad \text { Mendizabal } \\
2021[29]\end{array}$ & Thoracic & 256 patients & Classification & $\begin{array}{l}\text { ML can effectively classify pain using demographic } \\
\text { and clinical data }\end{array}$ \\
\hline $\begin{array}{l}\text { Gruss } 2015 \\
{[25]}\end{array}$ & $\begin{array}{l}\text { Evoked heat } \\
\text { pain }\end{array}$ & $\begin{array}{l}85 \text { subjects, age } \\
18-65 \text { years }\end{array}$ & Classification & $\begin{array}{l}\text { ML can effectively classify evoked pain using } \\
\text { biopotential data }\end{array}$ \\
\hline $\begin{array}{l}\text { Santra } 2020 \\
\quad[17]\end{array}$ & Low back & 30 patients & Diagnosis & $\begin{array}{l}\text { ML can effectively diagnose the cause of low back } \\
\text { pain }\end{array}$ \\
\hline $\begin{array}{l}\text { Rogachov } \\
2018[30]\end{array}$ & $\begin{array}{l}\text { Ankylosing } \\
\text { spondylitis }\end{array}$ & $\begin{array}{l}71 \text { patients and } 62 \\
\text { controls, age } \\
18-61 \text { years }\end{array}$ & Classification & ML can effectively classify pain using fMRI data \\
\hline $\begin{array}{l}\text { Grauhan } \\
2021[11]\end{array}$ & Shoulder & 2442 patients & Diagnosis & $\begin{array}{l}\text { ML can effectively diagnose the cause of shoulder } \\
\text { pain analysig plain X-rays }\end{array}$ \\
\hline $\begin{array}{l}\text { Darvishi } 2017 \\
\quad[10]\end{array}$ & Low back & $\begin{array}{l}92 \text { patients and } 68 \\
\text { controls, age } \\
29-50 \text { years }\end{array}$ & Manifestation & $\begin{array}{l}\text { ML can predict development of work-related low } \\
\text { back pain }\end{array}$ \\
\hline $\begin{array}{l}\text { Miettinen } \\
2021[14]\end{array}$ & Various causes & $\begin{array}{l}277 \text { patients, age } \\
18-77 \text { years }\end{array}$ & Classification & $\begin{array}{l}\text { ML can effectively predict pain based on sleep } \\
\text { patterns }\end{array}$ \\
\hline
\end{tabular}


Table 2 continued

\begin{tabular}{|c|c|c|c|c|}
\hline Study & Type of pain & Study population & Use of ML & Main findings \\
\hline $\begin{array}{l}\text { Fernandes } \\
2017[20]\end{array}$ & Osteoarthritis & $\begin{array}{l}1822 \text { subjects, age } \\
40-79 \text { years }\end{array}$ & Manifestation & $\begin{array}{l}\text { ML can effectively predict pain manifestation in } \\
\text { community-based population using clinical data }\end{array}$ \\
\hline $\begin{array}{l}\text { Lotsch } 2020 \\
\text { [22] }\end{array}$ & $\begin{array}{l}\text { Rheumatoid } \\
\text { arthritis }\end{array}$ & $\begin{array}{l}288 \text { patients, age } \\
18-70 \text { years }\end{array}$ & Manifestation & $\begin{array}{l}\text { ML can effectively predict pain manifestation using } \\
\text { demographic and clinical data }\end{array}$ \\
\hline $\begin{array}{l}\text { Tighe } 2020 \\
\text { [24] }\end{array}$ & Post-surgery & $\begin{array}{l}8071 \text { subjects, age } \\
\quad>21 \text { years }\end{array}$ & Manifestation & $\begin{array}{l}\text { ML can effectively predict acute pain manifestation } \\
\text { using clinical data }\end{array}$ \\
\hline $\begin{array}{l}\text { Tan } 2020 \\
\quad[31]\end{array}$ & Labor & 20,716 subjects & Manifestation & $\begin{array}{l}\text { ML can effectively predict pain manifestation } \\
\text { during labor using clinical data }\end{array}$ \\
\hline $\begin{array}{l}\text { Juwara } 2020 \\
\text { [28] }\end{array}$ & Cancer & $\begin{array}{l}195 \text { subjects, mean } \\
\text { age } 56 \text { years }\end{array}$ & Manifestation & $\begin{array}{l}\text { ML can effectively predict manifestation of } \\
\text { neuropathic pain using clinical data }\end{array}$ \\
\hline $\begin{array}{l}\text { Goldstein } \\
2020[33]\end{array}$ & $\begin{array}{l}\text { Low back } \\
\text { pain }\end{array}$ & $\begin{array}{l}65 \text { patients, age } \\
21-70\end{array}$ & Manifestation & $\begin{array}{l}\text { ML can effectively predict pain manifestation } \\
\text { based on clinical data }\end{array}$ \\
\hline $\begin{array}{l}\text { Yang } 2018 \\
\quad[32]\end{array}$ & $\begin{array}{l}\text { Sickle cell } \\
\text { disease }\end{array}$ & 40 patients & Classification & $\begin{array}{l}\text { ML can predict pain intensity using physiological } \\
\text { parameters }\end{array}$ \\
\hline $\begin{array}{l}\text { Pouromran } \\
2021[27]\end{array}$ & $\begin{array}{l}\text { Evoked heat } \\
\text { pain }\end{array}$ & $\begin{array}{l}87 \text { subjects, age } \\
18-65 \text { years }\end{array}$ & Classification & $\begin{array}{l}\text { ML can predict pain intensity using } \\
\text { electrophysiological parameters }\end{array}$ \\
\hline $\begin{array}{l}\text { Parthipan } \\
2019[23]\end{array}$ & Post-surgery & $\begin{array}{l}4306 \text { subjects, mean } \\
\text { age } 58 \text { years }\end{array}$ & Management & $\begin{array}{l}\text { ML can effectively predict the required opioids } \\
\text { dose for pain management }\end{array}$ \\
\hline $\begin{array}{l}\text { Ahn } 2018 \\
\quad[19]\end{array}$ & Osteoarthritis & $\begin{array}{l}40 \text { patients, age } \\
50-70 \text { years }\end{array}$ & Management & $\begin{array}{l}\text { ML demonstrated the effect of transcranial direct } \\
\text { current stimulation (tDCS) in the management } \\
\text { of pain }\end{array}$ \\
\hline $\begin{array}{l}\text { Wang } 2021 \\
\qquad[34]\end{array}$ & Cancer & 746 subjects & Management & $\begin{array}{l}\text { ML can effectively predict whether patients should } \\
\text { receive local treatment for pain due to bone } \\
\text { metastases }\end{array}$ \\
\hline
\end{tabular}

et al. used Bayesian networks to resolve diagnostic conflicts for the cause of LBP [17].

Prediction of manifestation of pain was also one of the commonest reasons for performing ML analysis. In a case control study, Darvishi et al. compared the neural network model approach with the logistic regression model approach in 92 workers with LBP and 68 healthy workers and showed that the former can predict more effectively the development of LBP [10]. Goldstein et al. built a mobile platform to predict patients' pain levels after a period of 2 weeks based on self-reported pain ratings and emotional state and found that a previous history of pain and fatigue are good predictors of pain [33]. In an open-label trial, Snyder et al. used a deep CNN model with which they used gyroscope and accelerometer data and classified the relative risk that lifting activities have for the development of back pain and injury, achieving an accuracy of $91 \%$ compared to an alternative $\mathrm{CNN}$ and multilayer perceptron (MLP) [18]. ML techniques were found to be effective in predicting even in real-time pain occurrence in a large cohort of postoperative patients, using numerous clinical variables retrieved through surgical records [24], which accurately helped the clinicians to provide the 
patient with appropriate pharmacological analgesics $[24,31]$. This was done via self-reported data such as pain intensity scales, emotional responses, quality of life, and an indication of the pain areas. Fernades et al., using a Bayesian modelling approach, developed a risk prediction model based on clinical parameters for the development of knee pain, regardless of underlying structural changes of knee osteoarthritis, which appeared to work well in a communitybased population [20]. Lötsch et al. analyzed demographic, patient-rated, and objective clinical factors and using ML identified early parameters that provided information about a future development of persistent pain in rheumatoid arthritis [22]. Juwara et al. identified baseline clinical data as predictive factors for neuropathic pain after breast cancer surgery using machine learning [28]. Finally, one study focused on measuring and predicting pain volatility, which was defined as the mean of absolute changes between two consecutive selfreported pain severity scores recorded via a mobile application [15].

Lastly, it was also demonstrated that ML for pain management has also been a key sector since it is empowering the reduction of negative body sensations and pain. Parthipan et al. studied the treatment of pain via prediction and prescription of the required opioid dose for managing pain due to osteoarthritis or postsurgery [23]. In their study, Ahn et al. used ML to demonstrate the effect of transcranial direct current stimulation (tDCS) in the management of pain [19]. In their study, Wang et al. developed and tested ML models to predict which patients with lung cancer and pain due to bone metastases should receive local treatment and found that a decision tree (DT) model was the most effective and accurate method for that aim [34].

\section{Techniques}

In the studies evaluated, a wide variety of ML algorithms were used. Most of these algorithms were supervised classification or regression techniques to address issues related to pain. The selected studies used mostly classical ML algorithms, such as SVM $[9,12,15,21,22,25-27]$, and random forest (RF) $[14,15,28,29,31,32]$ followed by Bayes $[17,19,20,22]$ techniques to classify tasks by assigning a predefined class label to an observation.

Numerous types of regression ML algorithms were also used by the reviewed studies $[10,15,23,27,28,30,32]$. This type of ML algorithm outputs continuous numerical values, rather than assigning a predefined class label to a data pattern.

Most of the reviewed studies used this ML technique to classify the patient's intensity of pain $[9,12,14,15,21,22,28]$. On the other hand, most of the reviewed studies which used the regression ML algorithms mostly predicted pain occurrence, probability, volatility, and management response, via a continuous set of data $[10,15,23,27,28,30,32]$.

The best performing ML algorithms were a boosting (i.e., FDboost), a regression (i.e., Elastic Net), and a neural network (NN), all three of which achieved a classification accuracy of more than $90 \%[10,13,23]$. The worst performing ML algorithm was a k-nearest neighbors $(\mathrm{kNN})$, which achieved a $52 \%$ accuracy [32]. Table 3 presents the data sources and size along with the ML methods and their accuracy.

\section{DISCUSSION}

More than half of the studies included in this review were published since 2020, which indicated that the use of ML for pain has increased over time. ML has been shown to be successful in learning how to map complex features to a known class.

The large number of papers in this literature review shows that the use of ML in research on pain has been of great importance and is considered to be highly beneficial for classifying, predicting, diagnosing, and managing pain This is because the amount of health-related data is rapidly expanding and large amounts of data are stored in clinical systems (i.e., a result of the advances in health technologies deployed in the medical sector) and personal consumer 


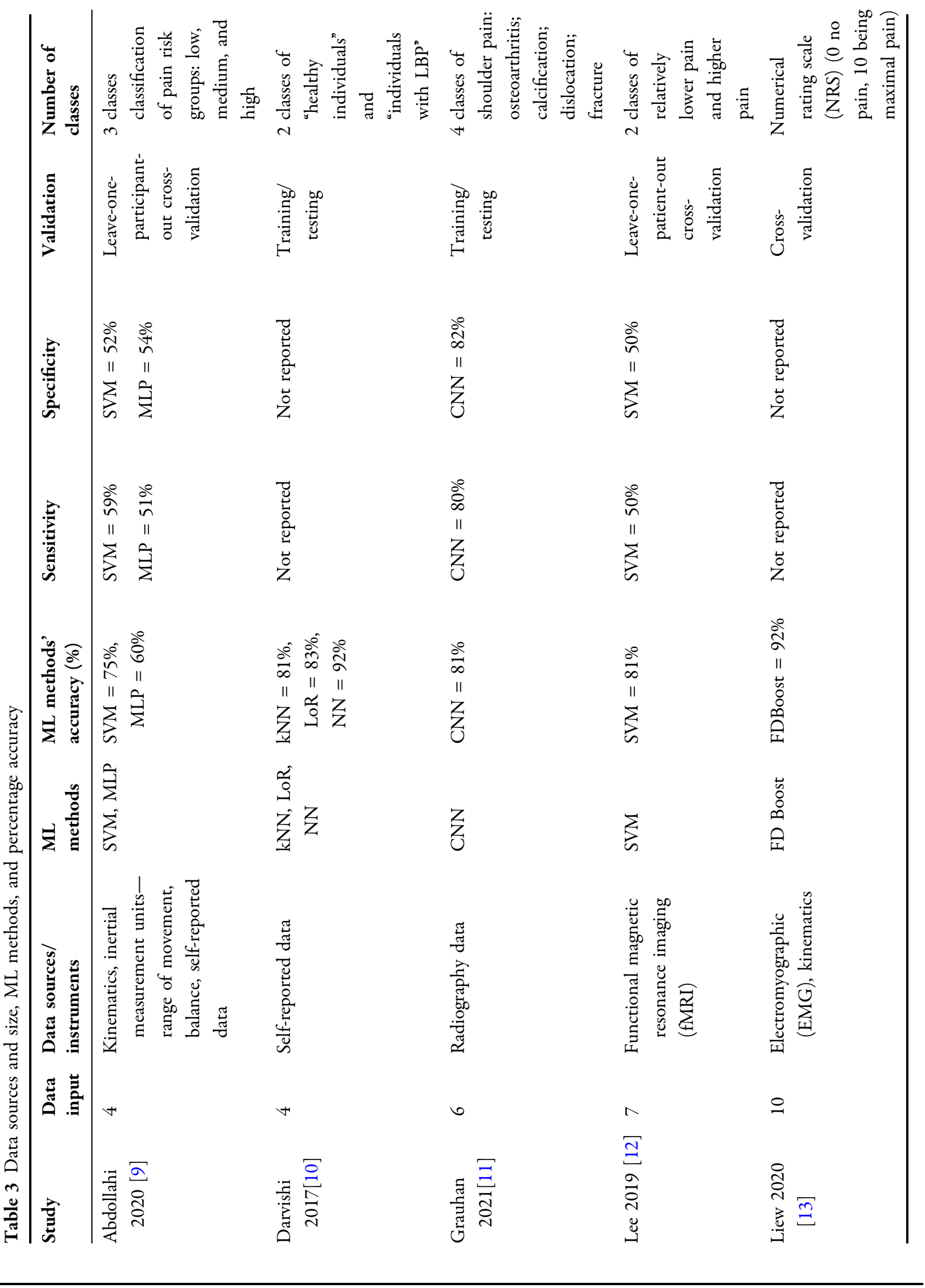




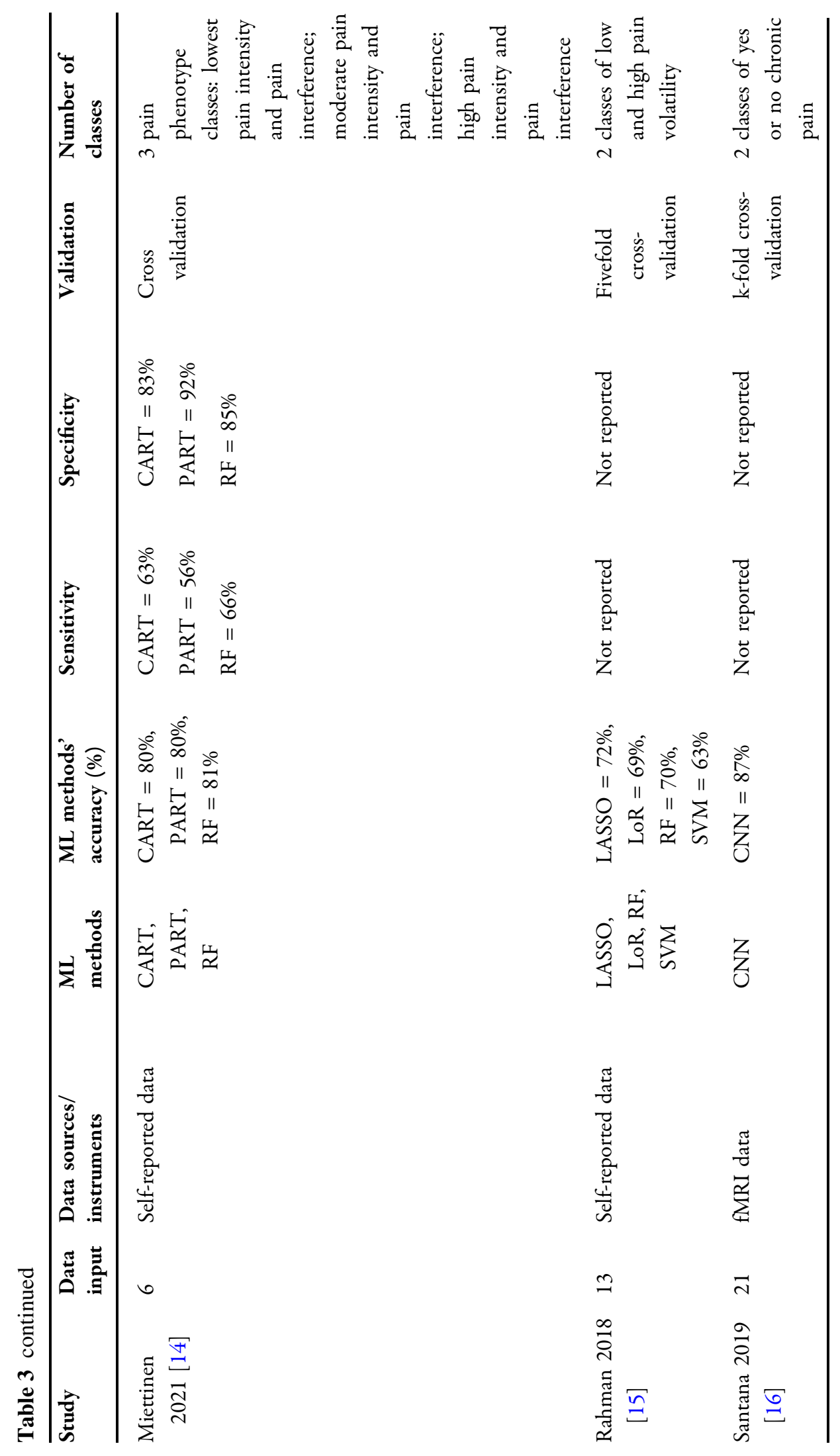




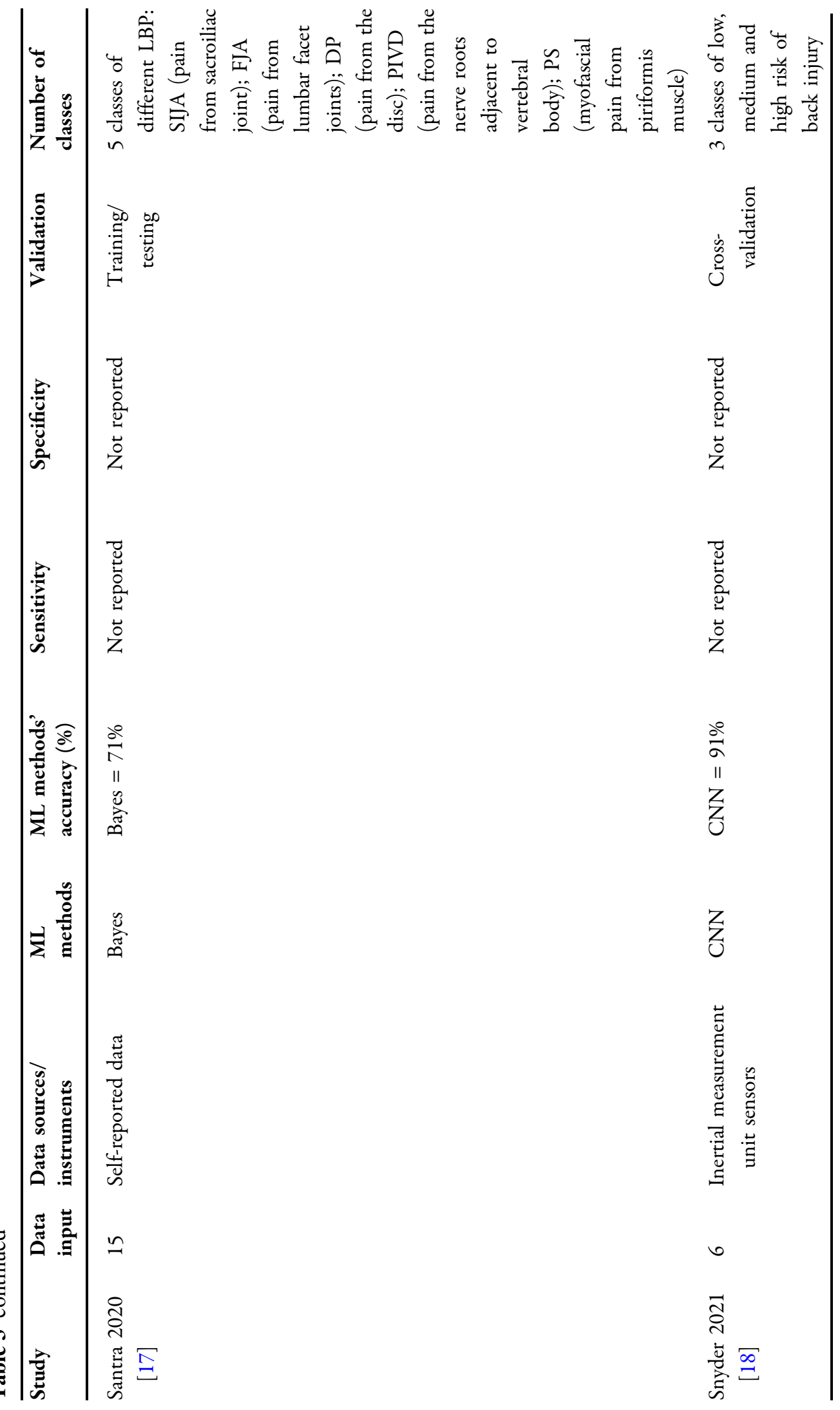




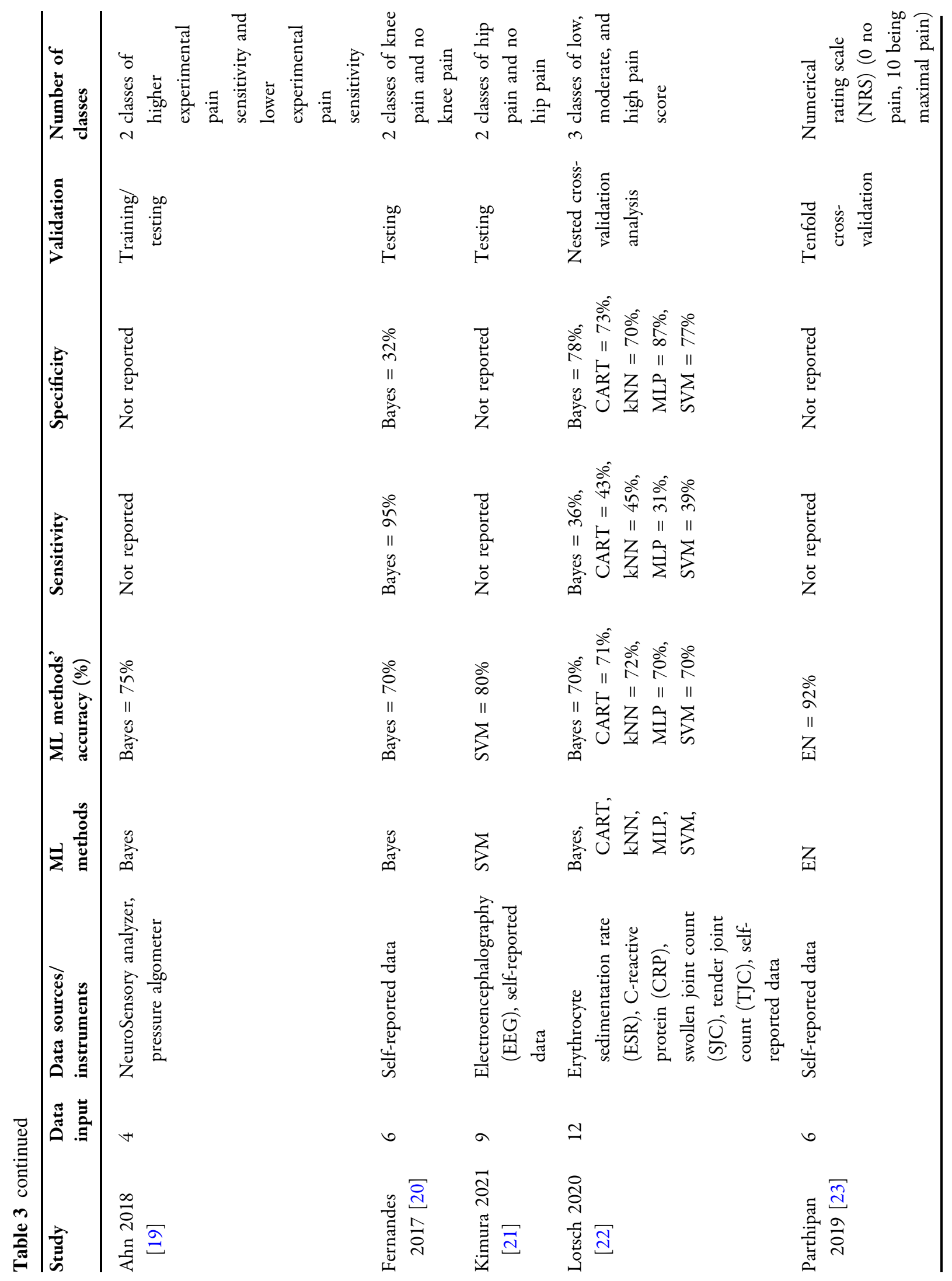




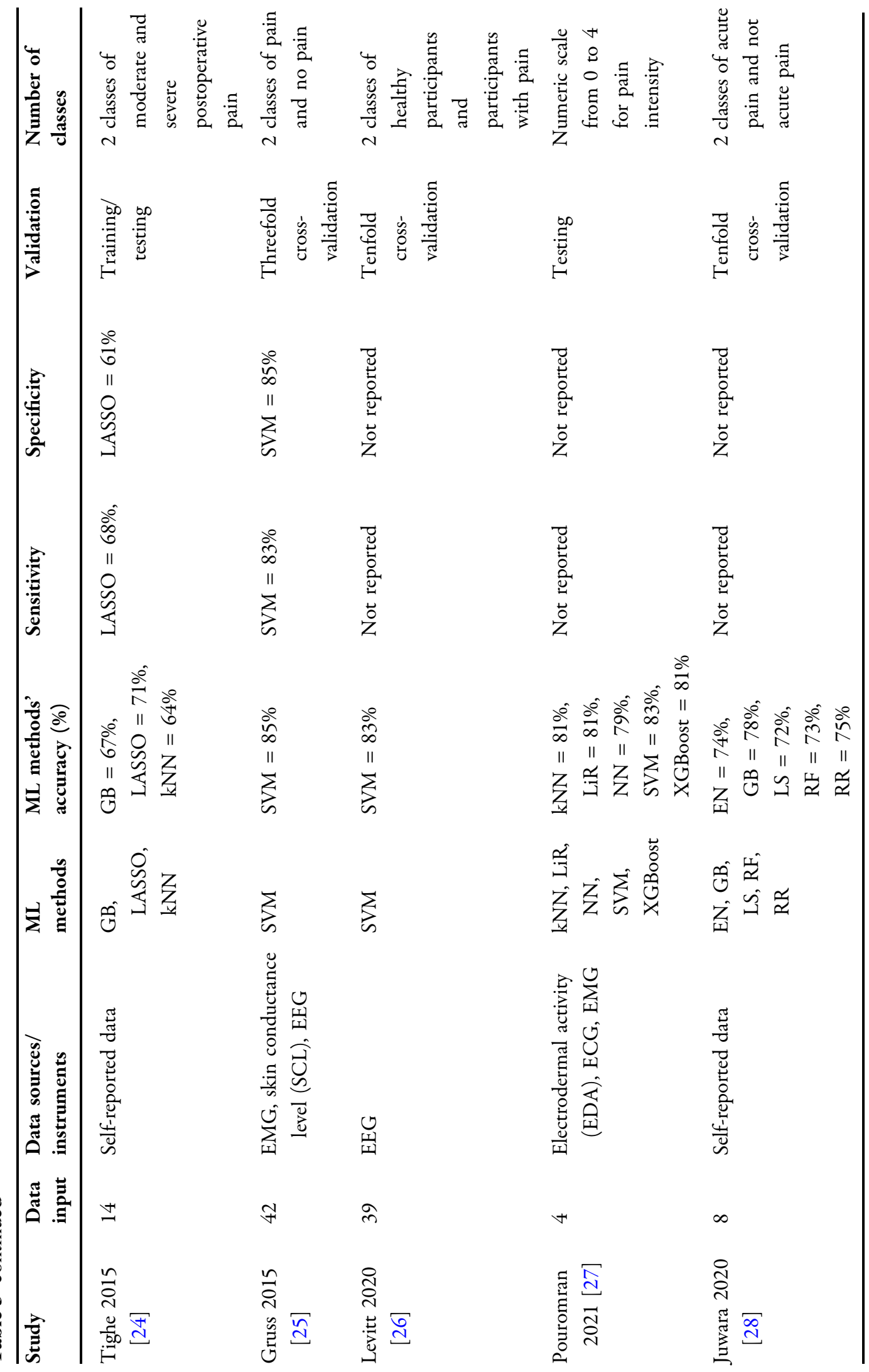




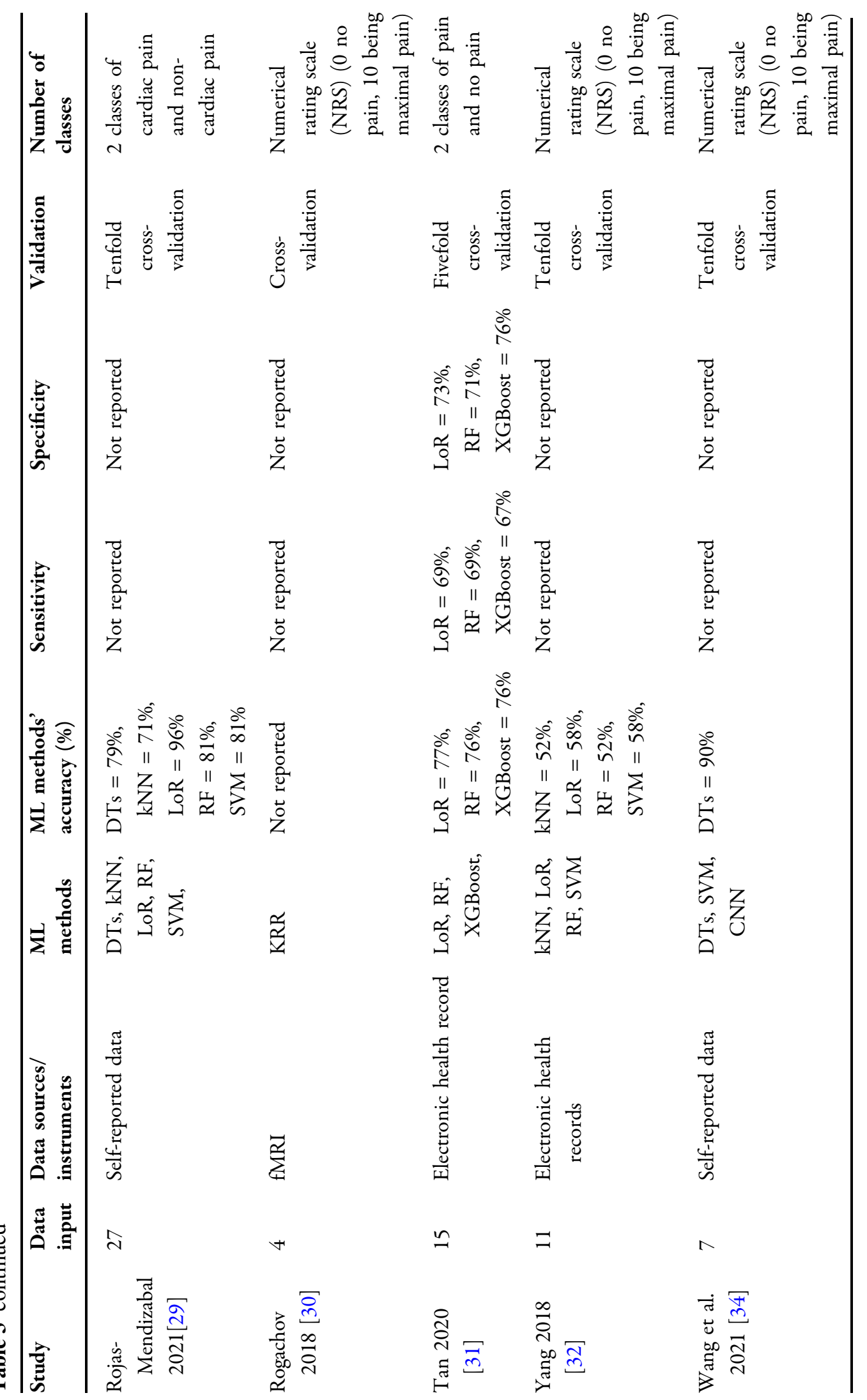




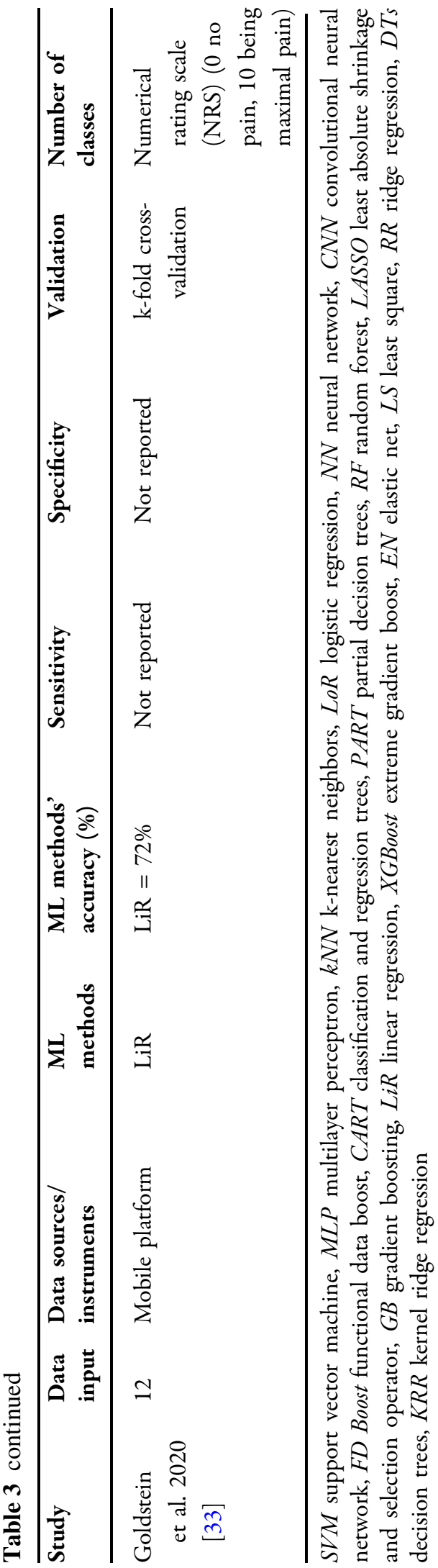

health devices such as mobile applications and wearables.

To improve the management and treatment of pain it is essential to be able to identify personalized healthcare treatment patterns. ML is considered to be beneficial because it succeeds at recognizing and predicting patterns, links, and relationships throughout big and complex datasets, independently of human supervision. As a result, ML was found to predict, classify, and suggest potential treatments of pain.

This review revealed that a wide variety of ML techniques have been employed in pain medicine. Most of these methods involve supervised classification or regression algorithms and contributed to the management of pain.

Our results should be interpreted with some caution given the limitations of our design. First, there was a great deal of heterogeneity between the studies, involving different interventions and different populations. Second, we only searched for publications in PubMed-albeit the largest medical database-and we therefore might have missed a few more papers that are indexed only in other databases.

\section{CONCLUSION}

Our review highlights the need for further use on ML in pain research in order to develop more algorithms that will be able to accurately predict and assist medical personnel in efficient diagnosis, successful decision-making, and effective treatment of pain. Furthermore, it is expected that explainable artificial intelligence systems will be developed to support decision-making [35] so that the medical personnel can better handle pain management.

\section{ACKNOWLEDGEMENTS}

Funding. No funding or sponsorship was received for this study or publication of this article. 
Authorship. All named authors meet the International Committee of Medical Journal Editors (ICMJE) criteria for authorship for this article, take responsibility for the integrity of the work as a whole, and have given their approval for this version to be published.

Author Contributions. Maria Matsangidou, Data analysis and interpretation, Drafting the article. Andreas Liampas, Data Collection. Drafting the article. Melpo Pittara, Data Collection. Constantinos S. Pattichi, Critical revision of the article. Panagiotis Zis, Conception or design of the work, data collection, data analysis, data interpretation, critical revision of the article.

Disclosures. Maria Matsangidou, Andreas Liampas, Melpo Pittara, Constantinos S. Pattichi and Panagiotis Zis have nothing to disclose.

Compliance with Ethics Guidelines. This article is based on previously conducted studies and does not contain any new studies with human participants or animals performed by any of the authors.

Data Availability. The datasets generated during and/or analyzed during the current study are available from the corresponding author on reasonable request.

Open Access. This article is licensed under a Creative Commons Attribution-NonCommercial 4.0 International License, which permits any non-commercial use, sharing, adaptation, distribution and reproduction in any medium or format, as long as you give appropriate credit to the original author(s) and the source, provide a link to the Creative Commons licence, and indicate if changes were made. The images or other third party material in this article are included in the article's Creative Commons licence, unless indicated otherwise in a credit line to the material. If material is not included in the article's Creative Commons licence and your intended use is not permitted by statutory regulation or exceeds the permitted use, you will need to obtain permission directly from the copyright holder. To view a copy of this licence, visit http://creativecommons.org/licenses/by$\mathrm{nc} / 4.0 /$.

\section{REFERENCES}

1. Arntz A, Claassens L. The meaning of pain influences its experienced intensity. Pain. 2004;109(1-2):20-5.

2. Merskey H, Bogduk N. Classification of chronic pain, IASP Task Force on Taxonomy. Seattle, WA: International Association for the Study of Pain Press (Also available online at www. iasp-painorg). 1994.

3. Moseley GL. A pain neuromatrix approach to patients with chronic pain. Man Ther. 2003;8(3): 130-40.

4. Price DD. Psychological mechanisms of pain and analgesia. Seattle: IASP Press; 1999.

5. Dhar V. Data science and prediction. Commun ACM. 2013;56(12):64-73.

6. IBM Cloud Education. 2021. Machine learning. IBM. https://www.ibm.com/cloud/learn/machinelearning\#toc-reinforcem-oVSqcdnf. Accessed 15 July 2021.

7. Murphy KP. Machine learning: a probabilistic perspective. Cambridge: MIT Press; 2012.

8. Moher D, Liberati A, Tetzlaff J, Altman DG, PRISMA Group. Preferred reporting items for systematic reviews and meta-analyses: the PRISMA statement. PLoS Med. 2009;6(7):e1000097.

9. Abdollahi $\mathrm{M}$, Ashouri S, Abedi $\mathrm{M}$, et al. Using a motion sensor to categorize nonspecific low back pain patients: a machine learning approach. Sensors. $2020 ; 20(12): 3600$.

10. Darvishi E, Khotanlou H, Khoubi J, Giahi O, Mahdavi N. Prediction effects of personal, psychosocial, and occupational risk factors on low back pain severity using artificial neural networks approach in industrial workers. J Manip Physiol Ther. 2017;40(7):486-93.

11. Grauhan NF, Niehues SM, Gaudin RA, et al. Deep learning for accurately recognizing common causes of shoulder pain on radiographs. Skelet Radiol. 2021. https://doi.org/10.1007/s00256-021-03740-9.

12. Lee J, Mawla I, Kim J, et al. Machine learning-based prediction of clinical pain using multimodal 
neuroimaging and autonomic metrics. Pain. 2019;160(3):550.

13. Liew BX, Rugamer D, De Nunzio AM, Falla D. Interpretable machine learning models for classifying low back pain status using functional physiological variables. Eur Spine J. 2020;29(8):1845-59.

14. Miettinen T, Mäntyselkä P, Hagelberg N, Mustola S, Kalso E, Lötsch J. Machine learning suggests sleep as a core factor in chronic pain. Pain. 2021;162(1): 109-23.

15. Rahman QA, Janmohamed T, Pirbaglou M, et al. Defining and predicting pain volatility in users of the manage my pain app: analysis using data mining and machine learning methods. J Med Internet Res. 2018;20(11):e12001.

16. Santana AN, Cifre I, de Santana CN, Montoya P. Using deep learning and resting-state fMRI to classify chronic pain conditions. Front Neurosci. 2019;17(13):1313. https://doi.org/10.3389/fnins. 2019.01313.PMID:31920483;PMCID:PMC6929667.

17. Santra D, Mandal JK, Basu SK, Goswami S. Medical expert system for low back pain management: design issues and conflict resolution with Bayesian network. Med Biol Eng Comput. 2020;58(11): 2737-56.

18. Snyder K, Thomas B, Lu ML, et al. A deep learning approach for lower back-pain risk prediction during manual lifting. PLoS One. 2021;16(2):e0247162. https://doi.org/10.1371/journal.pone.0247162.PMID: 33606783;PMCID:PMC7894914.

19. Ahn H, Suchting R, Woods AJ, et al. Bayesian analysis of the effect of transcranial direct current stimulation on experimental pain sensitivity in older adults with knee osteoarthritis: randomized sham-controlled pilot clinical study. J Pain Res. 2018;11:2071.

20. Fernandes GS, Bhattacharya A, McWilliams DF, Ingham SL, Doherty M, Zhang W. Risk prediction model for knee pain in the Nottingham community: a Bayesian modelling approach. Arthritis Res Ther. 2017;19(1):1-8.

21. Kimura A, Mitsukura Y, Oya A, et al. Objective characterization of hip pain levels during walking by combining quantitative electroencephalography with machine learning. Sci Rep. 2021;11(1):1.

22. Lötsch J, Alfredsson L, Lampa J. Machine-learningbased knowledge discovery in rheumatoid arthritisrelated registry data to identify predictors of persistent pain. Pain. 2020;161(1):114-26.

23. Parthipan A, Banerjee I, Humphreys K, et al. Predicting inadequate postoperative pain management in depressed patients: a machine learning approach. PLoS One. 2019;14(2):e0210575.

24. Tighe PJ, Harle CA, Hurley RW, Aytug H, Boezaart $\mathrm{AP}$, Fillingim RB. Teaching a machine to feel postoperative pain: combining high-dimensional clinical data with machine learning algorithms to forecast acute postoperative pain. Pain Med. 2015;16(7):1386-401.

25. Gruss S, Treister R, Werner P, et al. Pain intensity recognition rates via biopotential feature patterns with support vector machines. PLoS One. 2015;10(10):e0140330. https://doi.org/10.1371/journ al.pone.0140330.PMID:26474183;PMCID:PMC4608 770.

26. Levitt J, Edhi MM, Thorpe RV, et al. Pain phenotypes classified by machine learning using electroencephalography features. Neuroimage. 2020;223:117256.

27. Pouromran F, Radhakrishnan S, Kamarthi S. Exploration of physiological sensors, features, and machine learning models for pain intensity estimation. PLoS One. 2021;16(7):e0254108. https:// doi.org/10.1371/journal.pone.0254108.PMID:3424 2325;PMCID:PMC8270203.

28. Juwara L, Arora N, Gornitsky M, Saha-Chaudhuri P, Velly AM. Identifying predictive factors for neuropathic pain after breast cancer surgery using machine learning. Int J Med Inform. 2020;141: 104170 .

29. Rojas-Mendizabal V, Castillo-Olea C, Gómez-Siono A, Zuñiga C. Assessment of thoracic pain using machine learning: a case study from Baja California, Mexico. Int J Environ Res Public Health. 2021;18(4):2155. https://doi.org/10.3390/ijerph 18042155.PMID:33672112;PMCID:PMC7926745.

30. Rogachov A, Cheng JC, Hemington KS, et al. Abnormal low-frequency oscillations reflect traitlike pain ratings in chronic pain patients revealed through a machine learning approach. J Neurosci. 2018;38(33):7293-302.

31. Tan HS, Liu N, Sultana R, et al. Prediction of breakthrough pain during labour neuraxial analgesia: comparison of machine learning and multivariable regression approaches. Int J Obstet Anesth. 2021;1(45):99-110.

32. Yang F, Banerjee T, Narine K, Shah N. Improving pain management in patients with sickle cell disease from physiological measures using machine learning techniques. Smart Health (Amst). 2018;7(8):48-59. https://doi.org/10.1016/j.smhl. 2018.01.002. 
33. Goldstein P, Ashar Y, Tesarz J, Kazgan M, Cetin B, Wager TD. Emerging clinical technology: application of machine learning to chronic pain assessments based on emotional body maps. Neurotherapeutics. 2020;17(3):774-83.

34. Wang Z, Sun J, Sun Y, et al. Machine learning algorithm guiding local treatment decisions to reduce pain for lung cancer patients with bone metastases, a prospective cohort study. Pain Ther. 2021;10(1):619-33.

35. Holzinger A, Biemann C, Pattichis CS, Kell DB. What do we need to build explainable AI systems for the medical domain? arXiv preprint 1712 . 09923. 2017 Dec 28. 